Tropical Journal of Pharmaceutical Research December 2016; 15 (12): 2725-2731

ISSN: 1596-5996 (print); 1596-9827 (electronic)

(1) Pharmacotherapy Group, Faculty of Pharmacy, University of Benin, Benin City, 300001 Nigeria.

All rights reserved.

Available online at http://www.tjpr.org

Original Research Article

http://dx.doi.org/10.4314/tjpr.v15i12.27

\title{
Therapeutic effect of He-Wei-Tong-Xie decoction on acute pancreatitis complicated with gastrointestinal dysfunction
}

\author{
Wei Jin, Qing-Jie Li, Yang Song, Yi-Wei Li and Xiao-Yun Zhang* \\ Department of Emergency, Teaching Hospital of Chengdu University of Traditional Chinese Medicine, Chengdu 610075, PR \\ China \\ ${ }^{*}$ For correspondence: Email: jinweidoctor@163.com; Tel/Fax: +86-028-87766274
}

Received: 23 August 2016

Revised accepted: 20 November 2016

\begin{abstract}
Purpose: To study the therapeutic effect of He-Wei-Tong-Xie (HWXT) decoction on acute pancreatitis (AP) complicated with gastrointestinal dysfunction.

Methods: AP patients (50) were recruited from the Teaching Hospital of Chengdu University of Traditional Chinese Medicine and randomly divided into treatment and control groups (25 per group). All patients were evaluated at baseline, and thereafter subjected to standard therapeutic protocols, including, fasting, gastrointestinal decompression, administration of somatostatin and omeprazole. The patients in the treatment group also received $100 \mathrm{~mL}$ of HWTX by nasal route with high enema (three times/day). Gastrointestinal function scores (stomach ache, abdominal distension, borborygmus and defecation), and hospitalization time were evaluated on days 3 and 7 of treatment.

Results: No significant baseline differences were observed between the treatment and control groups with respect to etiological agents and AP syndrome scores $(p>0.05)$. However, after 3 and 7 days of treatment, all AP syndromes in treatment group showed significant improvement compared with the control patients $(p<0.01)$. There were no significant differences in hospitalization time and rate of recovery between the treatment and control groups $(p<0.01)$.

Conclusion: HWTX treatment appears to be a safe and potentially useful approach for treating AP complicated with gastrointestinal dysfunction.
\end{abstract}

Keywords: He-Wei-Tong-Xie decoction, Acute pancreatitis, Gastrointestinal dysfunction, Somatostatin, Omeprazole

Tropical Journal of Pharmaceutical Research is indexed by Science Citation Index (SciSearch), Scopus, International Pharmaceutical Abstract, Chemical Abstracts, Embase, Index Copernicus, EBSCO, African Index Medicus, JournalSeek, Journal Citation Reports/Science Edition, Directory of Open Access Journals (DOAJ), African Journal Online, Bioline International, Open-J-Gate and Pharmacy Abstracts

\section{INTRODUCTION}

Acute pancreatitis (AP), known as a common critical threatening disease in clinics, is a serious inflammatory disorder of the pancreas $[1,2]$. AP induces local and systemic complications, especially gastrointestinal dysfunction which could result in gut-derived infection, sepsis, multiple organ dysfunction syndromes (MODS), and death [2-4]. Although diagnostic technology for AP has improved appreciably over the years, effective treatment drugs with low side-effects are still lacking $[5,6]$.

It is well known that traditional Chinese medicine (TCM) has been used to treat various diseases for thousands years in China, and the curative effects of most of these TCM formulas have been demonstrated in modern pharmacological studies [7-9]. In addition, increasing investigations have indicated that TCM formulas offer feasible approaches for treating AP due to their promising 
effects on inflammatory and pain disorders, abdominal distension and constipation [8,10-12].

He-Wei-Tong-Xie (HWTX) decoction is an empirical TCM formula composed of Codonopsis pilosula, Poriacocos, Atractylodes macrocephala, Citrus reticulata, Pinellia ternate, Rheum palmatum, Citrus aurantium, Magnolia officinalis, Euphorbia kansui, Glycyrrhiza uralensis and Glauber salt (Table 1). It has been widely used in our hospital for treating acute pancreatitis complicated with gastrointestinal dysfunction. However, there have been no clinical or experimental studies on HWTX.

In the present study, we investigated the therapeutic effect of HWTX decoction on AP complicated with gastrointestinal dysfunction in patients from the Teaching Hospital of Chengdu University of Traditional Chinese Medicine.

\section{EXPERIMENTAL}

\section{Subjects}

The subjects were selected from patients admitted for treatments from June1, 2013 to December 30, 2014 in the Department of Emergency at The Affiliated Hospital of Chengdu University of Traditional Chinese Medicine (Chengdu, China). Male and female patients between the ages of 18 and 70 years were enrolled if they had definite diagnosis of AP. The diagnostic criteria were according to the Guidelines for the diagnosis and treatment of acute pancreatitis in China. These were (1) constant upper abdominal pain radiating to the back; (2) very high plasma levels of amylase and lipase (3 times the normal values) and (3) typical AP characteristic image changes by $\mathrm{CT} / \mathrm{MRI}$ or abdomen ultrasound. A definite diagnosis was indicated by detection of any two of these criteria. All patients were required to read and sign informed consent forms voluntarily before enrollment. The study protocols were approved by the Ethics Committee of the affiliated hospital of Chengdu University of Traditional Chinese Medicine (no. 2013KL-035) (Chengdu, China).

\section{Preparation of $\mathrm{He}$-Wei-Tong-Xie decoction}

HWTX is usually prepared by water decoction. Thus, the components of HWTX (Table 1) were decocted by auto drug decocting machine (North Pharmaceutical Equipment Manufacturing Co., Weifang, China) with $1500 \mathrm{~mL}$ of water after soaking for $30 \mathrm{~min}$. Extraction was done three times on the same sample. The extracts were pooled and filtered, and the clear supernatant was subsequently concentrated to $600 \mathrm{~mL}$ by using a rotary evaporator.

\section{Study design}

A total of 50 patients were divided randomly into treatment group and control group, each consisting of 25 patients. All patients were evaluated at baseline. Thereafter patients in both groups were treated with standard therapeutic protocols according to the Guidelines for the diagnosis and treatment of acute pancreatitis in China [13]. These included guardianship care, fasting, gastrointestinal decompression, and administration of somatostatin and omeprazole. Patients with biliary pancreatitis were given antibiotics and intravenous infusion. In addition to the standard treatments, the treatment group patients were administered $100 \mathrm{~mL}$ of HWTX by nasal feeding (three times/day), along with high enema, also given three times/day.

\section{Efficacy assessment}

Gastrointestinal function (stomachache scores, abdominal distension scores, borborygmus scores and defecation scores); hospitalization time, rate of disappearance of symptoms, and safety were evaluated at 3 and 7 days during treatment.

Table 1: Composition of HWTX

\begin{tabular}{lllc}
\hline Plant & Family & Part of plant & Weight \\
\hline Codonopsis pilosula & Campanulaceae & Root & $25 \mathrm{~g}$ \\
Poriacocos & Polypores & Sclerotium & $15 \mathrm{~g}$ \\
Atractylodes macrocephala & Asteraceae & Rhizoma & $12 \mathrm{~g}$ \\
Citrus reticulate & Rutaceae & Pericarp & $10 \mathrm{~g}$ \\
Pinellia ternate & Araceae & Tuber & $8 \mathrm{~g}$ \\
Rheum palmatum & Polygonaceae & Root \& Rhizoma & $10 \mathrm{~g}$ \\
Citrus aurantium & Rutaceae & Fruit & $10 \mathrm{~g}$ \\
Magnolia officinalis & Magnoliaceae & Cortex & $10 \mathrm{~g}$ \\
Euphorbia kansui & Euphorbiaceae & Tuber & $0.5 \mathrm{~g}$ \\
Glycyrrhiza uralensis & Leguminosae & Root & $10 \mathrm{~g}$ \\
Glauber salt & - & - & $10 \mathrm{~g}$ \\
\hline
\end{tabular}


The quantitative criteria for AP symptoms in our present investigation (Table 2) were drawn in line with previous reports $[3,13,14]$. In addition, gastrointestinal function recovery criteria were graded as: (1) clinical control: total scores decreasing $\geq 95 \%$; (2) markedly effective: total scores decreasing $\geq 70 \%$; (3) effective: total scores decreasing $\geq 30 \%$; (4) ineffective: total scores decreasing < $30 \%$; (5) or aggravated: total scores increasing $>0$.

\section{Safety evaluation}

Adverse reactions were recorded during the investigation. Body temperature, heart rate, respiratory rate and blood pressure were monitored and routine hemogram, urinalysis, and liver and renal function tests were performed. The onset time, severity, frequency, duration, counter-measures and consequences of adverse reactions were recorded in detail.

\section{Statistical analysis}

Data are expressed as mean $\pm S D$, and were analyzed using SPSS software (SPSS for windows 21.0, SPSS Inc, USA. Measurement data were analyzed by two-tailed t- test, while enumeration data were analyzed by Chi-square test. Grade comparison was by rank sum test. Differences were considered significant at $p<$ 0.05 .

\section{RESULTS}

\section{Baseline demographics and disease characteristics}

The baseline characteristics observed patients (age, breathing, body temperature and blood pressure) are shown in Table 3 while other baseline characteristics (white blood cell, WBC), neutrophil granulocyte, N), C reactive protein, CRP) and amylase are given in Table4. As can be seen from the Table, no statistically significant differences were observed between the treatment group and control group at baseline ( $p$ $>0.05$ ).

\section{AP scores}

A similar result was obtained for AP scores (Table 5). Compared with patients in control group, no difference was seen in patients of treatment group in stomach ache, abdominal distension, borborygmus, and failure of stool and gas pass $(p>0.05)$.

\section{Stomachache, abdominal distension, borborygmus and defecation scores}

After 3 and 7 days of treatment, we compared stomach ache, abdominal distension, borborygmus and defecation scores between the two groups. As can be seen from Tables 6 - 8, patients in treatment group showed significant improvement in all the syndromes of AP compared with the control patients $(p<0.01)$.

\section{Disappearance of AP symptoms, hospitalization time and adverse reactions after treatment}

Results for comparison of rate of disappearance of AP symptoms, hospitalization time and adverse reactions after treatment are shown on Tables 9 - 12. No significant differences were observed between the treatment and control groups with respect to these parameters $(p>$ 0.05).

Table 2: Quantitative criteria for symptoms of AP

\begin{tabular}{|c|c|c|c|c|}
\hline Variable & 0 & 2 & 4 & 6 \\
\hline Stomach & No & $\begin{array}{l}\text { Tolerable, } \\
\text { VAS:1-3 }\end{array}$ & $\begin{array}{l}\text { Occasional request for } \\
\text { analgesia; VAS: 4-6 }\end{array}$ & $\begin{array}{l}\text { Need analgesia, } \\
\text { VAS: } 7-10\end{array}$ \\
\hline $\begin{array}{l}\text { Abdominal } \\
\text { distension }\end{array}$ & No & $\begin{array}{l}\text { Tolerable, } \\
\text { VAS was 1-3 }\end{array}$ & $\begin{array}{l}\text { Abdominal distension, } \\
\text { VAS: } 4-6\end{array}$ & $\begin{array}{l}\text { Abdominal distension, } \\
\text { VAS: } 7-10\end{array}$ \\
\hline Borborygmus & $\begin{array}{l}\text { Normal } \\
(4-5 / \mathrm{min})\end{array}$ & $1-2 / \min$ & No & \\
\hline $\begin{array}{l}\text { Failure of stool } \\
\text { and intestinal } \\
\text { flatulence }\end{array}$ & No & $\begin{array}{l}\text { Failure of stool, } \\
\text { and defecation } \\
\text { after enema. }\end{array}$ & $\begin{array}{l}\text { Failure of stool, and } \\
\text { intestinal flatulence }\end{array}$ & \\
\hline
\end{tabular}

VAS: Visual Analogue Scale/Score 
Table 3: Baseline demographics and disease characteristics

\begin{tabular}{|c|c|c|c|c|}
\hline Variable & & Treatment $(n=25)$ & Control $(n=25)$ & $p$-value \\
\hline \multicolumn{5}{|l|}{ Age } \\
\hline & Mean & $49.72 \pm 13.67$ & $45.32 \pm 12.74$ & 0.2440 \\
\hline & Min-Max & $23.00-75.00$ & $25.00-71.00$ & \\
\hline & Med & 47.00 & 43.00 & \\
\hline & Q1-Q3 & $40.00-59.50$ & $35.50-54.50$ & \\
\hline \multicolumn{5}{|c|}{ Breathing } \\
\hline & Mean \pm SD & $26.28 \pm 2.85$ & $25.16 \pm 3.26$ & 0.2023 \\
\hline & Min-Max & $22.00-34.00$ & $20.00-34.00$ & \\
\hline & Med & 26.00 & 26.00 & \\
\hline & Q1-Q3 & $24.00-28.00$ & $22.00-26.50$ & \\
\hline \multicolumn{5}{|c|}{ Body temperature } \\
\hline & Mean $\pm \_S D$ & $37.24 \pm 0.84$ & $37.32 \pm 1.01$ & 0.7390 \\
\hline & Min-Max & $36.00-38.30$ & $36.00-39.20$ & \\
\hline & Med & 37.30 & 37.30 & \\
\hline & Q1-Q3 & $36.50-38.15$ & $36.50-38.25$ & \\
\hline \multicolumn{5}{|c|}{ Heart rate } \\
\hline & Mean $\pm \_S D$ & $96.40 \pm 15.93$ & $96.60 \pm 14.55$ & 0.9632 \\
\hline & Min-Max & $45.00-132.00$ & $62.00-135.00$ & \\
\hline & Med & 98.00 & 98.00 & \\
\hline & Q1-Q3 & $89.00-102.00$ & $88.50-102.50$ & \\
\hline \multicolumn{5}{|c|}{ Systolic pressure } \\
\hline & Mean \pm SD & $127.56 \pm 15.56$ & $123.24 \pm 17.25$ & 0.3572 \\
\hline & Min-Max & $101.00-170.00$ & $98.00-168.00$ & \\
\hline & Med & 123.00 & 122.00 & \\
\hline & Q1-Q3 & $119.50-136.00$ & $109.50-137.00$ & \\
\hline \multicolumn{5}{|c|}{ Diastolic pressure } \\
\hline & Mean \pm SD & $76.76 \pm 12.64$ & $77.64 \pm 10.64$ & 0.7912 \\
\hline & Min-Max & $48.00-111.00$ & $60.00-107.00$ & \\
\hline & Med & 73.00 & 76.00 & \\
\hline & Q1-Q3 & $69.00-82.50$ & $70.50-85.50$ & \\
\hline
\end{tabular}

Table 4: Baseline disease characteristics

\begin{tabular}{|c|c|c|c|}
\hline & Treatment $(n=25)$ & Control $(n=25)$ & $p$ value \\
\hline \multicolumn{4}{|l|}{ White blood cell } \\
\hline Normal & $9(36.00 \%)$ & $8(32.00 \%)$ & 0.7653 \\
\hline Abnormal & $16(64.00 \%)$ & $17(68.00 \%)$ & \\
\hline \multicolumn{4}{|l|}{ Neutrophils } \\
\hline Normal & $1(4.00 \%)$ & $3(12.00 \%)$ & 0.6092 \\
\hline Abnormal & $24(96.00 \%)$ & $22(88.00 \%)$ & \\
\hline \multicolumn{4}{|l|}{$C$ reactive protein } \\
\hline Normal & 19 (76.00\%) & $14(56.00 \%)$ & 0.1355 \\
\hline Abnormal & $6(24.00 \%)$ & $11(44.00 \%)$ & \\
\hline Normal & $2(8.00 \%)$ & $3(12.00 \%)$ & 1.0000 \\
\hline Abnormal & $23(92.00 \%)$ & $22(88.00 \%)$ & \\
\hline
\end{tabular}

Table 5: AP scores of patients before treatment

\begin{tabular}{lcccc}
\hline Variable & Score & Treatment $(\mathbf{n = 2 5})$ & Control $(\mathbf{n = 2 5})$ & $\boldsymbol{P}$-value \\
\hline Stomachache & 4.00 & $10(40 \%)$ & $10(40 \%)$ & 1.0000 \\
& 6.00 & $15(60 \%)$ & $15(60 \%)$ & \\
Abdominal distension & 2.00 & $2(8 \%)$ & $3(12 \%)$ & 0.4189 \\
& 4.00 & $15(60 \%)$ & $10(40 \%)$ & \\
Borborygmus & 6.00 & $8(32 \%)$ & $12(48 \%)$ & \\
Failure of stool and & 2.00 & $8(32 \%)$ & $10(40 \%)$ & 0.5597 \\
intestinal flatulence & 4.00 & $17(68 \%)$ & $15(60 \%)$ & \\
& 0.00 & $0(0 \%)$ & $2(8 \%)$ & 0.9545 \\
\hline
\end{tabular}


Table 6: Stomach ache scores of treatment and control groups

\begin{tabular}{lccccc}
\hline Variable & Score & Treatment $(\mathbf{n = 2 5})$ & Control $(\mathbf{n = 2 5})$ & $\mathbf{Z}$ & $\boldsymbol{P}$ value \\
\hline Before Treatment & 4.00 & $10(40.00 \%)$ & $10(40.00 \%)$ & 0.000 & 1.0000 \\
& 6.00 & $15(60.00 \%)$ & $15(60.00 \%)$ & & \\
Three days' treatment & 0 & $2(8 \%)$ & $0(0 \%)$ & & 0.0025 \\
& 2.00 & $11(44 \%)$ & $4(16 \%)$ & -3.024 & \\
& 4.00 & $11(44 \%)$ & $6(24 \%)$ & & \\
Seven days' treatment & 6.00 & $1(4 \%)$ & $0(0 \%)$ & & \\
& 0 & $4(16 \%)$ & $15(60 \%)$ & -3.032 & \\
& 2.00 & $19(76 \%)$ & $6(24 \%)$ & & \\
Intra-group comparison & 4.00 & $1(4 \%)$ & $4(16 \%)$ & & \\
\hline
\end{tabular}

Table 7: Abdominal distension scores of treatment and control groups

\begin{tabular}{lccccc}
\hline Variable & Score & Treatment $(\mathbf{n}=\mathbf{2 5})$ & Control $(\mathbf{n = 2 5})$ & $\mathbf{Z}$ & $P$-value \\
\hline Before treatment & 2.00 & $2(8 \%)$ & $3(12 \%)$ & -0.808 & 0.4189 \\
& 4.00 & $15(60 \%)$ & $10(40 \%)$ & & \\
Three days' treatment & 6.00 & $8(32 \%)$ & $12(48 \%)$ & & \\
& 2.00 & $19(76 \%)$ & $8(32 \%)$ & -3.369 & 0.0011 \\
Seven days' treatment & 4.00 & $6(24 \%)$ & $13(52 \%)$ & & \\
& 6.00 & $0(0 \%)$ & $4(16 \%)$ & & 0.0074 \\
& 0 & $10(40 \%)$ & $2(8 \%)$ & -2.678 & \\
& 2.00 & $11(44 \%)$ & $14(56 \%)$ & & \\
Intra-group comparison & 4.00 & $4(16 \%)$ & $6(2 \%)$ & & \\
\hline
\end{tabular}

Table 8: Borborygmus scores of treatment and control groups

\begin{tabular}{|c|c|c|c|c|c|}
\hline & Scores & Treatment $(n=25)$ & Control (n=25) & $\mathbf{Z}$ & $P$-value \\
\hline \multirow[t]{3}{*}{ Before Treatment } & 2.00 & $8(32 \%)$ & $10(40 \%)$ & -0.583 & 0.5597 \\
\hline & 4.00 & $17(68 \%)$ & $15(60 \%)$ & & \\
\hline & 0 & $6(24 \%)$ & $0(0 \%)$ & -3.159 & 0.0016 \\
\hline \multirow[t]{3}{*}{ Three days' treatment } & 2.00 & $16(64 \%)$ & $14(56 \%)$ & & \\
\hline & 4.00 & $3(12 \%)$ & $11(44 \%)$ & & \\
\hline & 0 & $10(40 \%)$ & $5(20 \%)$ & -2.367 & 0.0179 \\
\hline \multirow[t]{2}{*}{ Seven days' treatment } & 2.00 & $15(60 \%)$ & $14(56 \%)$ & & \\
\hline & 4.00 & $0(0 \%)$ & $6(24 \%)$ & & \\
\hline \multirow{2}{*}{ Intra-group comparison } & $\mathbf{Z}$ & -4.072 & -3.276 & & \\
\hline & $P$ value & 0.000 & 0.001 & & \\
\hline
\end{tabular}

Table 9: Defecation scores of treatment and control groups

\begin{tabular}{|c|c|c|c|c|c|}
\hline Variable & Scores & Treatment $(n=25)$ & Control $(n=25)$ & $\mathbf{Z}$ & $P$-value \\
\hline \multirow{3}{*}{ Before Treatment } & 0 & $0(0 \%)$ & $2(8 \%)$ & -0.057 & 0.9545 \\
\hline & 2.00 & $10(40 \%)$ & $7(28 \%)$ & & \\
\hline & 4.00 & $15(60 \%)$ & $16(64 \%)$ & & \\
\hline \multirow{3}{*}{ Three days' treatment } & 0 & $6(24 \%)$ & $1(4 \%)$ & -2.300 & 0.0215 \\
\hline & 2.00 & $18(72 \%)$ & $20(80 \%)$ & & \\
\hline & 4.00 & $1(4 \%)$ & $4(16 \%)$ & & \\
\hline \multirow{3}{*}{ Seven days' treatment } & 0 & $16(64 \%)$ & $13(52 \%)$ & -0.902 & 0.3668 \\
\hline & 2.00 & $8(32 \%)$ & $10(40 \%)$ & & \\
\hline & 4.00 & $1(4 \%)$ & $2(8 \%)$ & & \\
\hline \multirow{2}{*}{ Intra-group comparison } & $\mathbf{Z}$ & -4.388 & -3.697 & & \\
\hline & $P$ value & 0.000 & 0.000 & & \\
\hline
\end{tabular}


Table 10: Rate of disappearance of AP symptoms

\begin{tabular}{llcccc}
\hline Variable & Result & Treatment (n=25) & Control (n=25) & $\chi^{2}$ & $P$-value \\
\hline \multirow{2}{*}{ Stoma chache } & Disappeared & $4(16 \%)$ & $0(0 \%)$ & 4.348 & 0.1099 \\
& Existed & $21(84 \%)$ & $25(100 \%)$ & & \\
Abdominal & Disappeared & $10(40 \%)$ & $2(8 \%)$ & 7.018 & 0.0181 \\
distension & Existed & $15(60 \%)$ & $23(92 \%)$ & & \\
Borborygmus & Disappeared & $10(40 \%)$ & $5(20 \%)$ & 2.381 & 0.1228 \\
Failure of stool & Existed & $15(60 \%)$ & $20(80 \%)$ & & \\
and gas pass & Exappeared & $16(64 \%)$ & $12(52 \%)$ & 0.689 & 0.4064 \\
\hline
\end{tabular}

Table 11: Hospitalization time of treatment and control groups

\begin{tabular}{rccc}
\hline Variable & Treatment $(\mathbf{n}=24)$ & Control $(\mathbf{n = 2 1})$ & p value \\
\hline Full analysis set & & & \\
Mean_SD & $12.46 \pm 5.85$ & $18.10 \pm 4.96$ & 0.0000 \\
Min-Max & $6.00-36.00$ & $10.00-31.00$ & \\
Med & 11.50 & 18.00 & \\
Q1-Q3 & $9.00-13.75$ & $15.50-20.00$ & \\
Per protocol set & & & \\
Mean_SD & $12.46 \pm 5.85$ & $18.10 \pm 4.96$ & 0.0000 \\
Min-Max & $6.00-36.00$ & $10.00-31.00$ & \\
Med & 11.50 & 18.00 & \\
Q1-Q3 & $9.00-13.75$ & $15.50-20.00$ & \\
\hline
\end{tabular}

Table 12: Adverse reactions of treatment and control groups

\begin{tabular}{lccc}
\hline Variable & $\begin{array}{c}\text { Adverse } \\
\text { reactions }\end{array}$ & $\begin{array}{c}\text { Rate } \\
\%\end{array}$ & $\boldsymbol{P}$-value \\
\hline Treatment $(n=25)$ & 4 & 16.00 & 0.6671 \\
Control $(n=25)$ & 2 & 8.00 & \\
\hline
\end{tabular}

\section{DISCUSSION}

To the best of our knowledge, the present clinical report is the first experimental evidence regarding the therapeutic effects of HWTX decoction on AP complicated with gastrointestinal dysfunction. Interestingly and importantly, the results show that HWTX administration is beneficial in the treatment of AP with gastrointestinal dysfunction.

AP, a common acute abdominal disease, results from inflammatory reactions which damage the pancreas $[3,15]$. It causes acute stress, resulting in releases of various inflammatory cytokines and free radicals $[3,16]$. AP can easily lead to edema and erosion of digestive tract mucosa, resulting in the damage of mucosal barrier. This induces gut-derived infections due to translocation of gut bacterial endotoxin into blood $[3,12]$. Previous reports demonstrated that prognosis of AP patients can be greatly improved through recovery of gastrointestinal function and protection of gastrointestinal mucosal barrier. HWTX is derived from classical TCM formula of Large Chengqi Decoction and is composed of $C$. pilosula, P. cocos, A. macrocephala, C. reticulata, $P$. ternate, $R$. palmatum, $C$. aurantium, and $M$. officinalis. HWTX is an anti-bacterial agent which is also known to purge heat and flatulence from the bowels. Previous studies showed that the herbal components of HWTX possess significant beneficial effects against inflammatory reactions and gastrointestinal dysfunction $[12,17,18]$. In the present investigation, the results obtained indicate that HWTX in combination with standard AP treatment significantly improved AP syndromes when compared with control patients. The results also reveal that HWTX treatment is safe, with minimal side-effects.

\section{Limitation of the study}

In this work, the number of patients enrolled in the study is small, and therefore, a much higher number of patients would be required in future studies to validate the therapeutical effect of HWTX.

\section{CONCLUSION}

The findings of the present clinical study suggest that HWTX decoction is a safe and useful potential therapy for AP complicated with gastrointestinal dysfunction. However, further clinical studies are required confirm the findings obtained in this work. 


\section{DECLARATIONS}

\section{Acknowledgement}

This research was supported by the Hospital Fund of Teaching Hospital of Chengdu University of Traditional Chinese Medicine (no. 2013-D-YY07).

\section{Conflict of Interest}

No conflict of interest associated with this work.

\section{Contribution of Authors}

The authors declare that this work was done by the authors named in this article and all liabilities pertaining to claims relating to the content of this article will be borne by them.

\section{Open Access}

This is an Open Access article that uses a funding model which does not charge readers or their institutions for access and distributed under the terms of the Creative Commons Attribution License (http://creativecommons.org/licenses/by 14.0) and the Budapest Open Access Initiative (http://www.budapestopenaccessinitiative.org/rea d), which permit unrestricted use, distribution, and reproduction in any medium, provided the original work is properly credited.

\section{REFERENCES}

1. Wang GJ, Gao CF, Wei D, Wang C, Ding SQ: Acute pancreatitis: etiology and common pathogenesis. World J Gastroenterol 2009; 15: 1427-1430.

2. Santana $D G$, Santos $C A$, Santos $A D$, Nogueira $P C$, Thomazzi SM, Estevam CS, Antoniolli AR, Camargo $E A$ : Beneficial effects of the ethanol extract of Caesalpinia pyramidalis on the inflammatory response and abdominal hyperalgesia in rats with acute pancreatitis. J Ethnopharmacol 2012; 142: 445-455.

3. Thomasset SC, Carter CR: Acute pancreatitis. Surgery 2016; 34: 292-300.

4. The Spleen and Stomach Disease Branch of China Association of Chinese Medicine: Consensus on acute pancreatitis management of Chinese medicine. Chin $J$ TCM \& Pharm 2014; 28: 1826-1831.

5. Working Group IAP/APA: Acute Pancreatitis Guidelines. IAP/APA evidence-based guidelines for the management of acute pancreatitis. Pancreatol 2013; 13 (4 Suppl 2): e1-15.
6. Bukowczan J, Warzecha Z, Ceranowicz P, KuśnierzCabala B, Tomaszewska R, Dembinski A: Pretreatment with obestatin reduces the severity of ischemia/reperfusion-induced acute pancreatitis in rats. Eur J Pharmacol2015; 760: 113-121.

7. Peng $W$, Ming $Q L$, Han $P$, Zhang $Q Y$, Jiang $Y P$, Zheng $C J$, Han T, Qin LP: Anti-allergic rhinitis effect of caffeoylxanthiazonoside isolated from fruits of Xanthium strumarium L. in rodent animals. Phytomed 2014; 21: 824-829.

8. Zhao XL, Xiang J, Wan $M H, Y u Q$, Chen WW, Chen GY, Tang WF: Effect of acute pancreatitis on the pharmacokinetics of Chinese herbal ointment Liu-HeDan in an anesthetized rats. J Ethnopharmacol 2013; 145: 94-99.

9. Peng $W$, Hu $C L$, Shu $Z H$, Han $T$, Qin $L P$, Zheng $C J$ : Antitumor Activity of Tatariside $F$ isolated from roots of Fagopyrum tataricum (L.) Gaertn against $\mathrm{H} 22$ hepatocellular carcinoma via up-regulation of p53. Phytomed 2015; 22: 730-736.

10. Wu L, Li H, Zheng SZ, Liu X, Cai H, Cai BC: Da-HuangFu-Zi-Tang attenuates liver injury in rats with severe acute pancreatitis. J Ethnopharmacol 2013; 150: 960966.

11. Xiong J, Ni J, Hu G, Shen J, Zhao Y, Yang L, Shen J, Yin $G$, Chen $C$, Yu G, Hu Y, Xing M, Wan R, Wang X: Shikonin ameliorates cerulein-induced acute pancreatitis in mice. J Ethnopharmacol2013; 145: 573-580.

12. Lu X, Xiao W, Kang X, Yu J, Fan Z: The effect of Chinese herbal medicine on non-biliogenic severe acute pancreatitis: a systematic review and meta-analysis. $J$ Ethnopharmacol2014; 155: 21-29.

13. The Spleen and Stomach Disease Branch of China Association of Chinese Medicine: Guidelines for the diagnosis and treatment of acute pancreatitis in China. Chin J Gastroenterol 2013; 18: 428-433.

14. Qian AY, Zhang M: Guidelines for the treatment of acute pancreatitis in the United States of America. Chin $J$ Emerg Med 2013; 22: 1324-1325.

15. Mikolasevic I, Milic S, Orlic L, Poropat G, Jakopcic I, Franjic N, Klanac A, Kristo N, Stimac D: Metabolic syndrome and acute pancreatitis. Eur J Intern Med2016; 32: 79-83.

16. Hammer HF: An update on pancreatic pathophysiology (Do we have to rewrite pancreatic pathophysiology?).Wien Med Wochenschr 2014; 164: 57-62.

17. Zhang HT, Pan XF: Curative effect of Large Chengqi Decoction in treatment of severe acute pancreatitis and study on influence of serum TNF- $\alpha, \quad$ IL-6 and IL-8. Liaoning J TCM 2013; 40: 2052-2054.

18. He $X Y$, Liu QC, Peng W, Huang YL, Wu CJ. Bioactivities and serum pharmacochemistry of Qi-Wei-Xiao-YanTang. Pharm Biol2013; 51: 629-634. 